\title{
An Examination of Greenhouse Gas Convergence in OECD Countries
}

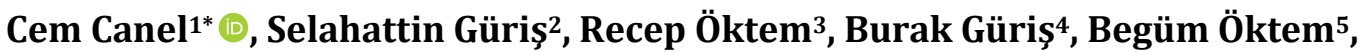 \\ Yaşar Serhat Yaşgül ${ }^{2}$, Muhammed Tıraşoğlu 6
}

\author{
${ }^{1}$ Congdon School of Supply Chain, Business Analytics and Information Systems, University of North Carolina Wilmington, \\ Wilmington, NC, USA \\ ${ }^{2}$ Department of Economics, Marmara University, Istanbul, Turkey \\ ${ }^{3}$ Department of Accounting and Finance, Marmara University, Istanbul, Turkey \\ ${ }^{4}$ Department of Econometrics, Istanbul University, Istanbul, Turkey \\ ${ }^{5}$ Department of Accounting and Tax Implications, Marmara University, Istanbul, Turkey \\ ${ }^{6}$ Department of Econometrics, Kirklareli University, Kirklareli, Turkey \\ Email: *canelc@uncw.edu
}

How to cite this paper: Canel, C., Güriş, S., Öktem, R., Güriş, B., Öktem, B., Yaşgül, Y.S. and Tiraşoğlu, M. (2020) An Examination of Greenhouse Gas Convergence in OECD Countries. Modern Economy, 11, $79-88$

https://doi.org/10.4236/me.2020.111008

Received: August 19, 2019

Accepted: January 11, 2020

Published: January 14, 2020

Copyright (C) 2020 by author(s) and Scientific Research Publishing Inc. This work is licensed under the Creative Commons Attribution International License (CC BY 4.0).

http://creativecommons.org/licenses/by/4.0/

\section{(c) (i) Open Access}

\begin{abstract}
Global warming has become one of the most critical factors affecting the world, especially in the last decade. Therefore, it is of great importance to analyze the impact of global warming and take measures. The main factor leading to global warming is considered to be people's consumption and production behaviors. The primary indicator of this is greenhouse gases. Relevant policy changes need to be made to control greenhouse gases. In this context, it is necessary to determine the differences in greenhouse gas emissions at the national level. To identify these differences, this study applies the convergence hypothesis, which has been the subject of numerous researchers since the 1980s. In this study, we analyzed the greenhouse gas intensity convergence for countries in the Organization for Economic Cooperation and Development (OECD) using linear and nonlinear panel unit root tests. The results of this study show that the greenhouse gas emissions in the OECD countries do not converge to the OECD average.
\end{abstract}

\section{Keywords}

Greenhouse Gas, Convergence Analysis, Linear Panel Unit Root Tests, Nonlinear Panel Unit Root Tests

\section{Introduction}

Today, global warming is one of the significant problems that affect the world 
and is projected to increase its impact in the upcoming years. The main factor leading to global warming is considered to be people's consumption and production behaviors. The primary indicator of this is greenhouses gases. Relevant policy changes need to be made in order to control greenhouse gases. Global warming and the resulting carbon emissions have become one of the most controversial topics in the world. Tremendous efforts are spent on increasing environmental awareness, especially since the 1970s, and reducing greenhouse gas emissions has become the very first priority of international meetings. Global politics and global economic interests stand as essential obstacles to getting concrete results from these efforts.

The OECD countries generate a significant portion of the greenhouse gas emissions in the world. The consequences of the policies that these countries currently implement regarding production and consumption patterns will have a substantial impact on how global warming will take shape in the future. Figure 1 presents the percent change in total greenhouse gas emissions since 1990 in the OECD countries and the world.

This study aims to analyze whether there is a convergence between the OECD countries regarding greenhouse gas emissions using linear and nonlinear time series and panel unit root tests. The convergence hypothesis, which has been the subject of many studies since the 1980s, is one of the necessary inferences of the neoclassical growth theory and suggests that the relatively developing countries would converge with the more prosperous countries by eliminating income differences in general terms. The theory of convergence has become a controversial issue that attracts the attention of economists since it was first introduced. Studies investigated how these current differences of countries, regions, or international organizations with different natural resource distribution and different income levels will continue. In other words, the issue of how the inequalities between economies will change constitutes the basis of convergence discussions.

Convergence is an attractive concept used in areas such as economic growth, finance, theoretical econometrics, European political and monetary union, regional planning as well as geography, entertainment, multimedia technology, and the software industry. The fact that the countries do not converge to the country group indicates that the applied policies differ. From this point of view, it possible to ensure that the country for which convergence findings cannot be obtained converges to the group of the country with a policy change. The convergence hypothesis can be empirically investigated using unit root tests. The rejection of the unit root hypothesis indicates the existence of convergence.

Unlike many of the other studies which use linear methods, this study uses the tests that focus on nonlinearity recently introduced in literature and frequently seen in economic structures.

The article is organized as follows. The next section presents the literature review. Econometric methods are introduced in section three. Section four provides the data and empirical findings used in the study, and conclusions and suggestions for further research are covered in section five. 


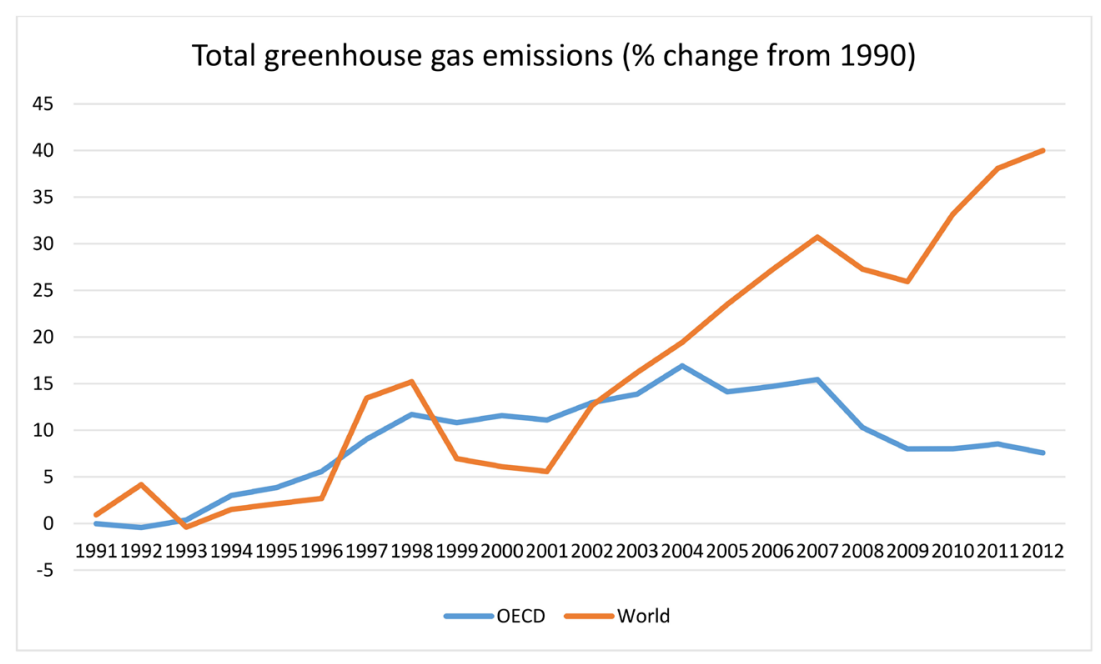

Figure 1. Total greenhouse gas emissions (\% charge from 1990).

\section{Literature Review}

El-Montassera et al. [1] investigated greenhouse gas emissions convergence among the G7 countries for the period between 1990 and 2011. They examined the convergence using the pairwise testing technique. The results obtained from this study do not confirm the hypothesis of convergence for the countries included in their study.

Strazicich and List [2] examined $\mathrm{CO}_{2}$ emission convergence among 21 industrialized countries. Their study concluded that convergence existed in the years between 1960 and 1997. Romero-Ávila, D. [3] examined the existence of stochastic and deterministic convergence of carbon dioxide emissions in 23 countries over the period 1960-2002 by employing the recently developed panel stationarity test. The results obtained from this study provided strong evidence supporting both stochastic and deterministic convergence in carbon dioxide emissions.

Lee and Chang [4] used the data for per capita carbon dioxide emissions relative to the average per capita emissions for 21 OECD countries covering the period 1960-2000. Empirical findings obtained from this paper provide evidence that relative per capita carbon dioxide emissions in OECD countries are a mixture of $\mathrm{I}(0)$ and $\mathrm{I}(1)$ processes, in which 14 out of 21 OECD countries exhibited divergence.

Barassi et al. [5] investigated the convergence of per capita carbon dioxide emissions in OECD countries for the period 1950-2002. This paper employed stationarity and unit root tests, including those that allow for cross-sectional dependencies within the panel. The results indicated that carbon dioxide emissions did not converge among OECD countries during the period under consideration. Barassi et al. [6] examined the convergence of carbon dioxide emissions within the OECD over the period 1870-2004. Their results suggest that carbon dioxide emissions within 13 out of 18 OECD countries are fractionally integrated, implying that they converge over time. 
Panopoulou and Pantelidis [7] examined convergence in carbon dioxide emissions among 128 countries for the period 1960-2003 utilizing a new methodology. Their results suggest convergence in per capita $\mathrm{CO}_{2}$ emissions among all the countries in the early years of the sample period. Li and Lin [8] examined the topic ( $\mathrm{CO}_{2}$ emissions) for 110 countries over the period 1971-2008. Their results showed that there was convergence within subgroups of countries with similar income levels, but no overall convergence was achieved.

This study is different from other studies in the sense that we use an empirical methodology and both linear and nonlinear panel unit tests, which have been recently introduced in the literature.

\section{Econometric Methods}

The econometric method used in the empirical part of the study is the linear and nonlinear panel unit root tests. It is clear that theoretical and practical studies on the panel data econometrics have considerably increased recently and that many researchers are interested in this topic. The reason for the growing interest in the panel data is that it offers certain advantages over using only time-series data or only horizontal cross-section data.

One of the most significant studies in the studies on advanced panel data techniques is the panel unit root tests. It is essential to determine whether the series or the panel analyzed is stationary in the search for a theory of economy or finance. In the analysis of panel data, classical panel unit root, panel unit root with breaks, and nonlinear panel unit root tests with different properties have been developed in determining whether the panel contains a unit root. In this study, we used linear and nonlinear panel unit root tests, which have certain advantages over classical time series methods. The next section explains the nonlinear panel unit root tests by Ucar and Omay [9] and Emirmahmutoğlu and Omay [10].

In the last quarter of a century, panel unit root applications have been expanded considerably in nonstationary panel data. Panel unit root tests are more powerful than standard time series unit root tests because they use both time-series and horizontal cross-section size [11]. The panel unit root tests utilized in the empirical part of the study are introduced here, respectively.

Several panel unit root tests are introduced in the panel data literature. One of these areas is the nonlinear panel unit root tests. These tests have a decade-old history and are limited. The use of nonlinear panel unit root tests gives more reliable results when the series to be employed in the analysis and the panel exhibit a nonlinear structure. In this context, Ucar and Omay [9] and Emirmahmutoğlu and Omay [10] tests are introduced.

Ucar and Omay [9] propose the unit root test for nonlinear heterogeneous panels by using the nonlinear time series framework Kapetanios, Shin, and Snell [12] test and the panel unit root testing framework of Im, Pesaran, and Shin [13] test. 
As suggested by Ucar and Omay [9] test, $y_{i, t}$ be the panel exponential smooth transition autoregressive process of order one $(\operatorname{PESTAR}(1))$ on the time domain $t=1,2, \cdots, T$ for the cross-section units $i=1,2, \cdots, N$ [14]. This test data generating process with the fixed effect parameter $\alpha_{i}$ is,

$$
\Delta y_{i, t}=\alpha_{i}+\phi_{i} y_{i, t-1}+\gamma_{i} y_{i, t-1}\left[1-\exp \left(-\theta_{i} y_{i, t-d}^{2}\right)\right]+\varepsilon_{i, t}
$$

in which case $d \geq 1$ is the delay parameter and $\theta_{i}>0$ implies the speed of mean reversion for all $i$.

Ucar and Omay [9] suggest that the panel unit root tests are computed by taking the average of individual Kapetanios, Shin, and Snell [12] test statistic. The Kapetanios, Shin, and Snell [12] statistic for the $i$ individual is simply $t$-ratio of $\delta_{i}$ in auxiliary regression defined by,

$$
t_{i, N L}=\frac{\Delta y_{i}^{\prime} M_{\tau} y_{i,-1}^{3}}{\hat{\sigma}_{i, N L}\left(y_{i,-1}^{\prime} M_{\tau} y_{i,-1}\right)^{3 / 2}}
$$

where $\hat{\sigma}_{i, N L}^{2}$ is the consistent estimator. Ucar and Omay [9] propose $\bar{t}_{N L}$ invariant average statistic for fixed $T$,

$$
\bar{t}_{N L}=\frac{1}{N} \sum_{i=1}^{N} t_{i, N L}
$$

where $t_{i, N L}$ is invariant concerning initial observations $y_{i, 0}$, heterogeneous moments $\sigma_{i}^{2}$ and $\sigma_{i}^{4}$ if $y_{10}=0$ for all $i=1,2, \cdots, N$. Individual statistic $t_{i, N L}$ are iid random variables with finite means and variances, an average statistic $\bar{t}_{i, N L}$ as defined in the previous equation have limiting standard normal distribution as $N \rightarrow \infty$ [9].

$$
\bar{Z}_{N L}=\frac{\sqrt{N}\left(\bar{t}_{N L}-E\left(t_{i, N L}\right)\right)}{\sqrt{\operatorname{Var}\left(t_{i, N L}\right)}} \stackrel{d}{\longrightarrow} N(0,1)
$$

where the values of $E\left(t_{i, N L}\right)$ and $\operatorname{Var}\left(t_{i, N L}\right)$ for different numbers of $T$ are tabulated in Table 1 by Ucar and Omay [9] [15].

Table 1. Linear panel unit root test results.

\begin{tabular}{ccccc}
\hline & Methane & Nitrous & CO2 & Greenhouse \\
\hline Levin, Lin and Chu [25] & 0.3278 & 0.1587 & $-3.989^{*}$ & $-2.0174^{*}$ \\
Harris and Tzavalis [20] & 0.9718 & 0.933 & 0.9468 & 0.9383 \\
Breitung [21] & 2.6478 & -0.0376 & 2.6297 & 2.8004 \\
Im, Pesaran and Shin [22] & -1.0118 & 0.5619 & $-1.7418^{*}$ & -1.5236 \\
Maddala and Wu [19] & 48.1682 & 54.5412 & 69.0915 & 51.1836 \\
Choi [24] & 43.6091 & $74.2681^{*}$ & $101.79^{*}$ & $82.7779^{*}$ \\
Hadri [23] & 87.0710 & 103.349 & 121.916 & 99.4581 \\
Pesaran t-bar [13] & -1.0630 & -1.8640 & -1.7940 & -1.5460 \\
\hline
\end{tabular}

Note: The symbol * means rejection of the null hypothesis of a unit root. Source: Authors' calculation. 
Emirmahmutoglu and Omay [10] propose the panel asymmetric nonlinear unit root test as an extended version of the asymmetric ESTAR unit root test by Sollis [16], which allows for symmetric or asymmetric nonlinear adjustment under the alternative hypothesis to a unit root [17].

The unit root test by Kapetanios et al. [12] only assumes symmetric mean reversion behavior, but the unit root test by Sollis [16] takes into account asymmetric behavior. Sollis [16] can be extended to nonlinear asymmetric heterogeneous panels as follows:

$$
\begin{gathered}
\Delta y_{i t}=G_{i t}\left(\gamma_{1 i}, y_{i, t-1}\right) \times\left\{S_{i t}\left(\gamma_{2 i}, y_{i, t-1}\right) \rho_{1 i}+\left(1-S_{i t}\left(\gamma_{2 i}, y_{i, t-1}\right)\right) \rho_{2 i}\right\} y_{i, t-1}+\varepsilon_{i t} \\
G_{i t}\left(\gamma_{1 i}, y_{i, t-1}\right)=1-\exp \left(-\gamma_{1 i} y_{i, t-1}^{2}\right), \quad \gamma_{1 i} \geq 0 \text { for all } i, \\
S_{i t}\left(\gamma_{2 i}, y_{i, t-1}\right)=\left[1+\exp \left(-\gamma_{2 i} y_{i, t-1}\right)\right]^{-1}, \quad \gamma_{2 i} \geq 0 \text { for all } i,
\end{gathered}
$$

where $\varepsilon_{i t} \sim \operatorname{iid}\left(0, \sigma_{i}^{2}\right)$. In this case, the deviation is the negative of the state variable, the outer regime is $\Delta y_{i t}=\rho_{i 2} y_{i, t-1}+\varepsilon_{i t}$, and the deviation is in the positive direction, and the outer regime is $\Delta y_{i t}=\rho_{i 1} y_{i, t-1}+\varepsilon_{i t}$, where the transition function takes the extreme values 0 and 1, respectively, for these two cases.

Emirmahmutoglu and Omay [10] suggest replacing $G_{i t}\left(\gamma_{1 i}, y_{i, t-1}\right)$ in the first equation with a first-order Taylor expansion around $\gamma_{1 i}=0$ gives as follows:

$$
\Delta y_{i t}=\rho_{1 i} \gamma_{1 i} y_{i, t-1}^{3} S_{i t}\left(\gamma_{2 i}, y_{i, t-1}\right)+\rho_{2 i} \gamma_{1 i} y_{i, t-1}^{3}\left(1-S_{i t}\left(\gamma_{2 i}, y_{i, t-1}\right)\right)+\varepsilon_{i t}
$$

The augmented auxiliary equation is obtained as

$$
\Delta y_{i t}=\phi_{1 i} y_{i, t-1}^{3}+\phi_{2 i} y_{i, t-1}^{4}+\sum_{j=1}^{p_{i}} \delta_{i j} \Delta y_{i, t-j}+\varepsilon_{i t}
$$

The proposed test statistic is computed by taking the average of the individual $F_{i, A E}$ statistic.

$$
\bar{F}_{A E}=N^{-1} \sum_{i=1}^{N} F_{i, A E}
$$

Sollis [16] proposed using the individual $t$ statistic $\left(t_{i, A E}^{a s}\right)$ with the standard $t$ distribution. Emirmahmutoglu and Omay [10] compute $\bar{t}_{A E}^{a s}$, taking the average of the individual statistic with the standard distribution. They suggest a sequential panel selection method (SPSM) by Chortareas and Kapetanios [18].

\section{Data and Empirical Results}

The convergence of the intensity and the components of the greenhouse gas concentrations for OECD countries have been analyzed using linear and nonlinear time series and panel unit root tests. The data utilized in the study were obtained from the World Bank-World Development Indicators database. The variables are $\mathrm{CO}_{2}$, Methane, Nitrous, and total greenhouse gas. The data of 29 OECD countries for the period 1970-2012 were investigated in the study. Czech Republic, Germany, Estonia, Latvia, Slovakia, and Slovenia were not included in the study. 
In this part of the study where per capita greenhouse gas convergence in OECD countries is investigated, linear and nonlinear panel methods have been used, which attract the attention of many researchers and have significant advantages in empirical studies. The linear panel unit root test results and the nonlinear panel unit root test results for greenhouse gas convergence are shown in Table 1 and Table 2, respectively.

The validity of the greenhouse gas convergence in Table 1 was investigated applying the tests by Maddala et al. [19], Harris and Tzavallis [20], Breitung [21], Im et al. [22] and Pesaran [13]. According to findings, the null hypothesis of a unit root was not rejected in all unit root tests for per capita methane gas, and stationarity null hypothesis was rejected in the Hadri stationarity test [23]. According to these results, per capita, methane gas convergence in OECD countries does not converge. For the nitrous gas per person, only the null hypothesis of a unit root was rejected in the Choi [24] test, and no stationarity was detected in cases other than this test. The unit root test hypothesis was rejected for $\mathrm{CO}_{2}$ gas per capita according to the results of Levin et al. [25], Im et al. [22], and Choi [24] tests. In other words, per capita, $\mathrm{CO}_{2}$ gas convergence is applied in OECD countries. In the last column, the analysis results for total greenhouse gas per capita were given. According to this, Levin et al. [25] and Choi [24] tests showed that per capita greenhouse convergence was valid, while the other six tests were the opposite. In general, it is concluded that convergence is not the case mostly by looking at the results of per capita greenhouse gas linear panel unit root tests in the OECD countries.

In Table 2, the validity of per capita greenhouse gas convergence in OECD countries was investigated using Ucar and Omay [9] and Emirmahmutoglu and Omay [10] tests from nonlinear panel unit root tests. According to Ucar and Omay [9] and Emirmahmutoğlu and Omay [10] tests for methane gas per capita, the null hypothesis of a unit root is not rejected; in other words, the methane gas convergence is not valid. Both test results for nitrous gas per capita indicate the presence of a unit root. Similarly, both of the test results indicate the presence of a unit root for per capita $\mathrm{CO}_{2}$ gas. Finally, the presence of the null hypothesis of a unit root cannot be rejected according to the results of both tests for per capita total greenhouse gas; in other words, convergence is not valid. Looking at the results of greenhouse gas nonlinear panel unit root tests per capita in OECD countries in general, we conclude that convergence is not valid in all cases.

Table 2. Nonlinear panel unit root test results.

\begin{tabular}{ccccc}
\hline & Methane & Nitrous & $\mathrm{CO}_{2}$ & Greenhouse \\
\hline Ucar and Omay [9] & -1.3850 & -1.4890 & -1.5970 & -1.4450 \\
Emirmahmutoglu and Omay [10] & 1.7330 & 1.9570 & 2.2290 & 2.3580
\end{tabular}

Note: The symbol * means rejection of the null hypothesis of unit root. Source: Authors' calculation. 


\section{Conclusions}

Global warming is on the rise in the world and is expected to have more impact in the upcoming years. Different measures have been taken in recent years to control global warming. In this context, the convergence of greenhouse gas, which is regarded as the core indicator of global warming, for OECD countries is necessary to guide policy makers.

The convergence analysis has been carried out in recent years using linear and nonlinear panel unit root tests in the literature. The conclusion is that the convergence of per capita greenhouse gas emissions in OECD countries is not valid. The findings indicate that the long-term greenhouse gas emissions in the OECD countries will not be close to the same long-term values. According to these results, the differences in the long-term greenhouse gas emissions in the OECD countries will not disappear. Various policy changes need to be made in order to take these gases under control.

Future studies can focus on a similar analysis for country groups. Different results could be obtained from homogenous country groups.

\section{Conflicts of Interest}

The authors declare no conflicts of interest regarding the publication of this paper.

\section{References}

[1] El-Montasser, G., Inglesi-Lotz, R. and Gupta, R. (2015) Convergence of Greenhouse Gas Emissions among G7 Countries. Applied Economics, 47, 6543-6552. https://doi.org/10.1080/00036846.2015.1080809

[2] Strazicich, M.C. and List, J.A. (2003) Are $\mathrm{CO}_{2}$ Emission Levels Converging among Industrial Countries? Environmental and Resource Economics, 24, 263-271. https://doi.org/10.1023/A:1022910701857

[3] Romero-Ávila, D. (2008) Convergence in Carbon Dioxide Emissions among Industrialised Countries Revisited. Energy Economics, 30, 2265-2282. https://doi.org/10.1016/j.eneco.2007.06.003

[4] Lee, C.C. and Chang, C.P. (2008) New Evidence on the Convergence of Per Capita Carbon Dioxide Emissions from Panel Seemingly Unrelated Regressions Augmented Dickey-Fuller Tests. Energy, 33, 1468-1475. https://doi.org/10.1016/j.energy.2008.05.002

[5] Barassi, M.R., Cole, M.A. and Elliott, R.J. (2008) Stochastic Divergence or Convergence of Per Capita Carbon Dioxide Emissions: Re-Examining the Evidence. Environmental and Resource Economics, 40, 121-137. https://doi.org/10.1007/s10640-007-9144-1

[6] Barassi, M.R., Cole, M.A. and Elliott, R.J. (2011) The Stochastic Convergence of $\mathrm{CO}_{2}$ Emissions: A Long Memory Approach. Environmental and Resource Economics, 49, 367-385. https://doi.org/10.1007/s10640-010-9437-7

[7] Panopoulou, E. and Pantelidis, T. (2009) Club Convergence in Carbon Dioxide Emissions. Environmental and Resource Economics, 44, 47-70.

https://doi.org/10.1007/s10640-008-9260-6 
[8] Li, X. and Lin, B. (2013) Global Convergence in Per Capita $\mathrm{CO}_{2}$ Emissions. Renewable and Sustainable Energy Reviews, 24, 357-363. https://doi.org/10.1016/j.rser.2013.03.048

[9] Ucar, N. and Tolga, O. (2009) Testing for Unit Root in Nonlinear Heterogeneous Panels. Economics Letters, 104, 5-8. https://doi.org/10.1016/j.econlet.2009.03.018

[10] Emirmahmutoglu, F. and Tolga, O. (2014) Reexamining the PPP Hypothesis: A Nonlinear Asymmetric Heterogeneous Panel Unit Root Test. Economic Modelling, 40, 184-190. https://doi.org/10.1016/j.econmod.2014.03.028

[11] Mario, C. and Nicholas, S. (2007) A Bootstrap Panel Unit Root Test under Cross-Sectional Dependence, with an Application to PPP. Computational Statistics \& Data Analysis, 51, 4028-4037. https://doi.org/10.1016/j.csda.2006.12.025

[12] Kapetanios, G., Shin, Y. and Snell, A. (2003) Testing for a Unit Root in the Nonlinear STAR Framework. Journal of Econometrics, 112, 359-379. https://doi.org/10.1016/S0304-4076(02)00202-6

[13] Pesaran, M.H. (2007) A Simple Panel Unit Root Test in the Presence of Cross-Section Dependence. Journal of Applied Econometrics, 22, 265-312. https://doi.org/10.1002/jae.951

[14] Karadagli, E.C. and Nazlı, C.O. (2012) Testing Weak Form Market Efficiency of Emerging Markets: A Nonlinear Approach. Journal of Applied Economic Sciences, 7, 235-245.

[15] Bozoklu, Ş. and Yilanci, V. (2014) Current Account Sustainability in Emerging Markets: An Analysis with Linear and Nonlinear Panel Unit Root Tests. Atatürk Üniversitesi İktisadi ve İdari Bilimler Dergisi, 28, 251-264.

[16] Sollis, R. (2009) A Simple Unit Root Test against Asymmetrical STAR Nonlinearity with an Application to Real Exchange Rates in Nordic Countries. Economic Modelling, 26, 118-125. https://doi.org/10.1016/j.econmod.2008.06.002

[17] Bahmani-Oskooee, M., Tsangyao, C. and Kuei-Chiu, L. (2016) Panel Asymmetric Nonlinear Unit Root Test and PPP in Africa. Applied Economics Letters, 23, 554-558. https://doi.org/10.1080/13504851.2015.1088132

[18] Chortareas, G. and Kapetanios, G. (2009) Getting PPP Right: Identifying Mean-Reverting Real Exchange Rates in Panels. Journal of Banking and Finance, 33, 390-404. https://doi.org/10.1016/j.jbankfin.2008.08.010

[19] Maddala, G.S. and Shaowen, W. (1999) A Comparative Study of Unit Root Tests with Panel Data and A New Simple Test. Oxford Bulletin of Economics and Statistics, 61, 631-652. https://doi.org/10.1111/1468-0084.61.s1.13

[20] Harris, R.D.F. and Elias, T. (1999) Inference for Unit Roots in Dynamic Panels Where the Time Dimension İs Fixed. Journal of Econometrics, 91, 203-205. https://doi.org/10.1016/S0304-4076(98)00076-1

[21] Breitung, J. (2001) The Local Power of Some Unit Root Tests for Panel Data. İn: Nonstationary Panels, Panel Cointegration, and Dynamic Panels, Emerald Group Publishing Limited, Bingley, 161-167. https://doi.org/10.1016/S0731-9053(00)15006-6

[22] Im, K.S., Hashem, P. and Yongcheol, S. (2003) Testing for Unit Roots in Heterogeneous Panels. Journal of Econometrics, 115, 53-74. https://doi.org/10.1016/S0304-4076(03)00092-7

[23] Hadri, K. (2000) Testing for Stationarity in Heterogeneous Panel Data. Econometrics Journal, 3, 148-161. https://doi.org/10.1111/1368-423X.00043

[24] Choi, I. (2001) Unit Root Tests for Panel Data. Journal of International Money and 
Finance, 20, 249-272. https://doi.org/10.1016/S0261-5606(00)00048-6

[25] Levin, A., Chien-Fu, L. and Chia-Shang, J.C. (2002) Unit Root Tests in Panel Data: Asymptotic and Finite-Sample Properties. Journal of Econometrics, 108, 1-24. https://doi.org/10.1016/S0304-4076(01)00098-7 